\title{
EL CUENTO HISTÓRICO PARA LA ENSEÑANZA DE LA PROBABILIDAD EN LA EDUCACIÓN PRIMARIA EN BRASIL
}

\section{THE HISTORICAL TALE CONTRIBUTING TO THE TEACHING OF PROBABILITY IN ELEMENTARY EDUCATION IN BRAZIL \\ O CONTO HISTÓRICO CONTRIBUINDO PARA O ENSINO DE PROBABILIDADE NO ENSINO FUNDAMENTAL NO BRASIL}

\author{
Ailton Paulo de Oliveira Júnior \\ Karoline Marcolino Cardoso Barão \\ Universidade Federal do ABC, Santo André, Brasil \\ Recibido: 02/04/2021 - Aceptado: 13/07/2021 - Publicado: 11/12/2021 \\ Remita cualquier duda sobre esta obra a: Ailton Paulo de Oliveira Júnior. \\ Email:ailton.junior@ufabc.edu.br
}

\begin{abstract}
RESUMEN
Este estudio tuvo como objetivo investigar el aprendizaje probabilístico con un grupo de estudiantes de cuarto año de la escuela primaria en Brasil, tomando en cuenta situaciones que involucran conceptos básicos de probabilidad, como el espacio muestral y sus eventos, a través de la narrativa utilizada en una historia corta. “¿Sabías que los niños jugaban con el juego de baldosas hace mucho tiempo, en Francia?”. La Teoría de Situaciones Didácticas - TSD fue el soporte para la evaluación de la actividad de intervención, buscando el desarrollo de competencias y habilidades relacionadas con la probabilidad. Los resultados indican que los estudiantes fueron capaces de identificar los elementos históricos traídos a la narrativa y que la propuesta de juego propuesta por el Conde de Buffon, presentando conceptos elementales de probabilidad, sirvió como motivador y elemento para la aprehensión del conocimiento probabilístico. Indicamos que, en respuesta a la pregunta de investigación, los resultados obtenidos proporcionaron una fuerte evidencia de que las actividades contribuyeron a la enseñanza y el aprendizaje de la Probabilidad. Además, los resultados mostraron las dificultades experimentadas por algunos de los estudiantes en la adquisición de conocimientos, y los errores cometidos nos llevaron a pensar en diferentes enfoques para la apropiación de conocimientos.
\end{abstract}

Palabras clave: Enseñanza de la probabilidad; Cuento y Juego histórico; Años iniciales de la escuela primaria; Teoría de las situaciones didácticas. 


\begin{abstract}
This study aimed to investigate probability learning with a group of fourth-year elementary school students in Brazil, considering situations involving basic concepts of probability, such as sampling space and its events, through the narrative used in a short story. history called: "Did you know that children played with the tile game a long time ago, in France?”. The Theory of Didactic Situations - TSD was support for the assessment of the intervention activity, seeking the development of competences and abilities related to probability. The results indicate that the students were able to identify the historical elements brought into the narrative and that the game proposal proposed by the Count of Buffon, presenting elementary concepts of probability (sample space, events, randomness, etc.), served as a motivating element for the apprehension of probabilistic knowledge. We indicate that, in response to the research question, the results obtained provided strong evidence that the activities contributed to the teaching and learning of Probability. In addition, the results showed the difficulties experienced by some of the students in acquiring knowledge, and the mistakes made led us to think of different approaches to appropriating knowledge.
\end{abstract}

Keywords: Probability Teaching; Tale and Historical game; Initial years of elementary school; Theory of Didactic Situations.

\title{
RESUMO
}

O presente estudo teve por objetivo investigar a aprendizagem de probabilidade com um grupo de alunos do quarto ano do Ensino Fundamental no Brasil, levando em consideração situações envolvendo conceitos básicos de probabilidade, como espaço amostral e seus eventos, por meio da narrativa utilizada em um conto histórico denominado: "Você sabia que as crianças brincavam com o jogo dos ladrilhos há muito tempo atrás, na França?". A Teoria das Situações Didáticas - TSD foi suporte para a avaliação da atividade de intervenção, buscando o desenvolvimento de competências e habilidades relativas à probabilidade. Os resultados indicam que os alunos conseguiram identificar os elementos históricos trazidos na narrativa e que a proposta do jogo proposto pelo Conde de Buffon, apresentando conceitos elementares da probabilidade (espaço amostral, eventos, aleatoriedade, etc.), serviu como elemento motivador para a apreensão do conhecimento probabilístico. Indicamos que, em resposta à questão de pesquisa, os resultados obtidos forneceram fortes evidências de que as atividades contribuíram para o ensino e aprendizagem da Probabilidade. Além disso, os resultados evidenciaram as dificuldades vividas por alguns dos alunos na aquisição de conhecimentos, sendo que os erros cometidos nos orientaram a pensar em diferentes abordagens para a apropriação do conhecimento.

Palavras-chave: Ensino de Probabilidade; Conto e Jogo histórico; Anos iniciais do Ensino Fundamental; Teoria das Situações Didáticas.

\section{INTRODUCCIÓN}

En lo que respecta a la enseñanza de la probabilidad, Vásquez y Alsina (2017), recomiendan que los alumnos en su formación inicial, las ideas probabilísticas deben ser abordadas de manera informal, vinculándolas a situaciones provenientes de un contexto cotidiano, propiciando el uso de un lenguaje cotidiano e informal propio, que permita introducir y resaltar nociones de probabilidad necesarias para que los alumnos avancen progresivamente hacia una comprensión y aplicación de los conceptos básicos de probabilidad. 
En Brasil, desde 1997, el contenido probabilístico se incluye en el bloque de contenido denominado "Procesamiento de la información" en los Parámetros Curriculares Nacionales de Matemáticas (Ministerio de Educación, 1997) y, recientemente, en la Base Curricular Común Nacional (Ministerio de Educación, 2018), en la unidad temática titulada "Probabilidad y Estadística" que aborda, por ejemplo, la noción de azar como uno de los primeros objetos de conocimiento para la educación inicial de los estudiantes de educación básica.

Gal (2004) señala que la alfabetización probabilística debe construirse con los estudiantes desde el inicio de su escolaridad, dado que conceptos como probabilidad deben trabajarse a través de diferentes perspectivas como: predictibilidad de un concepto, incertidumbre, calcular/comunicar probabilidades, lenguaje, contexto del concepto, cuestiones críticas que involucran diferentes situaciones para el concepto.

El autor también considera que existe la necesidad de que las personas pasen por la alfabetización probabilística para lidiar con la amplia gama de situaciones del mundo real que involucran la generación o interpretación de mensajes probabilísticos, así como la toma de decisiones sobre los fenómenos que aparecen (Gal, 2004).

Batanero (2015) al discutir la enseñanza y el aprendizaje de la probabilidad con los niños indica que se debe: (1) Brindar experiencias con situaciones aleatorias; (2) Ayudar que los niños desarrollen un lenguaje para describirlos; (3) Considerar intuiciones previas, aunque erróneas, y ayudándoles a confrontar los datos de las experiencias; (4) Conectar la probabilidad con las otras materias matemáticas y otras disciplinas.

Así, definimos como objetivo de este trabajo, investigar el aprendizaje de estudiantes de cuarto año de la escuela primaria en una escuela pública del estado de São Paulo - Brasil a través de la Teoría de Situaciones Didácticas - TSD, considerando un cuento histórico y un juego, también histórico, y proponer situaciones que involucran conceptos básicos de probabilidad como aleatoriedad, espacio muestral y eventos aleatorios.

Con base en estos puntos de vista, la investigación apostó por un subsidio metodológico teórico que parte de la presentación de un juego a través de un cuento histórico, involucrando contenidos probabilísticos que favorecen la aproximación entre las actividades cotidianas realizadas por los estudiantes (de manera espontánea), y las actividades desarrolladas en un entorno escolar.

En esta investigación, la TSD sirvió de soporte para la evaluación de una actividad que busca el desarrollo de competencias y habilidades relacionadas con las nociones básicas de probabilidad.

Para lograr nuestro objetivo, el abordaje de esta investigación fue cualitativo, teniendo como parámetro la Base Curricular Nacional Común (BNCC) que aporta los contenidos y las habilidades a trabajar en la unidad temática "Probabilidad y Estadística” para los primeros años de la escuela primaria, considerando la importancia de la probabilidad para la educación de los ciudadanos. 


\section{HISTORIA DE LA PROBABILIDAD, JUEGOS Y CUENTOS PARA LA ENSEÑANZA DE LA PROBABILIDAD PARA DURANTE LOS PRIMEROS AÑOS DE LA ESCUELA PRIMARIA}

Alsina y Vásquez (2017) consideran que, para comenzar a enseñar probabilidad, debemos partir de situaciones de incertidumbre en el entorno del niño, pues a través de estas comenzarán a usar su propio lenguaje probabilístico ante un determinado evento: imposible, probable o seguro, por ejemplo. Además, el docente debe proporcionarles experiencias que les permitan observar la probabilidad de los fenómenos y, mediante estimulación (preguntas, proyectos de trabajo que parten de una pregunta de investigación, observar/calcular, predecir etc.), pedirles que expresen las posibles predicciones.

Para complementar estas ideas, Coutinho (2007) discutió el papel de la historia en la elección de contextos para presentar los primeros conceptos probabilísticos en la escuela primaria. Para realizar un estudio epistemológico, describió la aprehensión del azar en relación con el contexto en el que se inserta, considerando los posibles resultados de manipulaciones de un generador de azar, como los juegos de azar (manipulación de monedas, dados, etc.).

Oliveira Júnior et al. (2017), consideraron importante los argumentos que refuerzan las potencialidades pedagógicas y cuestionadoras de la Historia de las Matemáticas, según Miguel (1997), apoyado en la investigación bibliográfica sobre Historia de la Probabilidad y desarrollo de actividades para el uso en las aulas de Educación Básica haciendo referencia a conceptos probabilísticos básicos.

De esta forma, el uso de la historia puede potenciar el aprendizaje de determinados contenidos probabilísticos, ya que los alumnos abordan los contenidos de forma globalizada con otros alumnos, con los contenidos de lectura relacionados con el entorno emocional y afectivo. Esto facilita que los alumnos se pongan en contacto con situaciones probabilísticas, ajenas al mundo infantil, si las abordamos de forma contextualizada.

Además de los aspectos enumerados anteriormente, los juegos siempre han jugado un papel importante en el aprendizaje, porque fomentan el pensamiento lógico matemático (Kamii \& Rummelsburg, 2008) y contribuyen al desarrollo del conocimiento e influyen positivamente en el componente afectivo o emocional de las situaciones de aprendizaje (Booker, 2000).

Específicamente, los juegos tienen el potencial de incrementar el interés y los niveles de motivación de los estudiantes (Bragg, 2007). Así, los juegos educativos ofrecen una oportunidad para integrar aspectos cognitivos, afectivos y sociales del aprendizaje (Pulos \& Sneider, 1994).

Considerando la enseñanza de la probabilidad, Vásquez y Alsina (2014) proponen para el estudio de conceptos probabilísticos el uso de materiales concretos como fichas, dados y juegos de azar, ya que serán de gran ayuda en la realización de experimentos aleatorios que reforzarán conceptos probabilísticos. 
Creemos que los juegos se pueden utilizar con estudiantes de una amplia gama de habilidades. Esta flexibilidad se debe a la naturaleza motivacional de los juegos y la atracción que los estudiantes tienen naturalmente por los juegos y el trabajo con materiales prácticos. Ofrecen a los estudiantes oportunidades para aprender conceptos específicos, como probabilidad, y para sacar conclusiones en sus respectivos niveles.

Asociando juegos de azar y aspectos históricos, Viali (2008) recuerda que la primera manifestación de juegos que se registra es el Tali (juego de huesos) que se jugaba con el astrágalo, un hueso de animal con forma similar a un tetraedro irregular.

También creamos historias, contamos las nuestras, creamos juegos y las vivimos, como si su desarrollo, sus tramas y reglas, acompañaran nuestro propio desarrollo, en el que necesitamos adaptarnos a lo que nos imponen. Interpretamos los cuentos según nuestros sentidos (Estés, 2005), y los entendemos, según nuestras vivencias, la misma relación que se da en los juegos (Freire \& Scaglia, 2003). Somos seres culturales y sociales, por lo que el entorno influye y está influenciado por quiénes somos.

Por lo tanto, consideramos el cuento como un recurso que puede promover el trabajo probabilístico durante el proceso de enseñanza-aprendizaje (Mateus et al., 2013) porque el cuento se convierte en un recurso que puede brindar múltiples beneficios a los estudiantes, ya que permite aprender en un entorno globalizador y significativo para el niño (Ministerio de Educación, 2018).

\section{MARCO TEÓRICO}

Consideramos que el objeto central de la TSD es la situación didáctica que se define según Brousseau (1978) como el conjunto de relaciones que se establecen explícita y/o implícitamente entre un alumno o grupo y los alumnos, un determinado milieu que puede contener instrumentos u objetos y un sistema educativo para que los estudiantes adquieran conocimientos constituidos o en constitución.

Además de estos aspectos, Almouloud (2014) destaca situaciones adidácticas que son parte esencial de situaciones didácticas, donde la intención de enseñar no se revela al alumno, sino que se imagina, planifica y construye (en el caso de esta obra, la narrativa del juego histórico) para brindar estas condiciones favorables para la apropiación de un nuevo saber.

En este trabajo y basado en Brousseau (1986), las situaciones adidácticas tendrán las siguientes características: (1) El problema probabilístico se elige de manera que permita al alumno actuar, hablar, reflexionar y evolucionar por iniciativa propia y consideramos que el juego histórico permite el desarrollo de estas acciones; (2) Los problemas se elaboraron pensando que el alumno adquiere nuevos conocimientos y que están justificados por la lógica interna de la situación y que se construyen sin apelar a las razones didácticas, es decir, el aprendizaje debe partir de su propia necesidad y no por una aparente necesidad del maestro o de la escuela; (3) El investigador / docente asumirá el rol de mediador (solo el 
narrador), creando condiciones para que el alumno sea el actor principal en la construcción de su conocimiento a partir de las actividades propuestas en la narrativa del juego histórico.

Según Almouloud (2014), para analizar el proceso de aprendizaje, la TSD observa y desglosa este proceso en cuatro fases, en las que el conocimiento tiene diferentes funciones y el alumno no tiene la misma relación con el conocimiento. En estas fases interconectadas se pueden observar situaciones de acción, formulación, validación e institucionalización.

Almouloud (2014) destaca que para Brousseau las situaciones adidácticas están modelados en términos de juego, es decir, una situación que es probable que provoque el aprendizaje será tal que el estudiante tenga una estrategia básica para comenzar a jugar y las estrategias creadas deben permitirle comprender el problema y las reglas del juego. Es de destacar que la retroalimentación brindada por el milieu permite al alumno darse cuenta de que la estrategia establecida no le permitirá ganar el juego, pero que se debe crear o posibilitar una estrategia óptima para obtener los conocimientos propuestos por el juego pedagógico.

Según Brousseau (1986), la TSD busca desarrollar un modelo de interacción entre el estudiante (aprendiz), el conocimiento y el milieu en el que se debe desarrollar el aprendizaje. El objeto central de la teoría no es lo que él llama sujeto cognitivo, sino la situación didáctica en la que se identifican las interacciones que se establecen entre profesor, alumno y conocimiento.

El milieu involucra las relaciones entre los estudiantes, entre el maestro y el estudiante y el instrumento utilizado para promover el aprendizaje (cuento). Consideramos que entre los estudiantes y el conocimiento del grupo en la resolución de problemas, el milieu del grupo es parte del milieu de los estudiantes.

Para comprender mejor en qué consiste cada situación didáctica, en el momento en que los niños participan de la historia a través del juego histórico, consideramos que se trabajan los cuatro tipos de situaciones, a saber:

1. Situación de acción - Los participantes toman decisiones, poniendo en práctica sus conocimientos para resolver el problema, lo que da como resultado un conocimiento que no está formulado probabilísticamente. A partir del cuento, los participantes pueden llegar a la conclusión de que la información histórica ayuda en el proceso de apropiación de conceptos probabilísticos.

2. Situación de formulación - se lleva a los estudiantes a explicar las estrategias utilizadas. Para eso, necesitan formularlos verbalmente, transformando el conocimiento implícito en explícito. El alumno reanuda su acción a otro nivel y se apropia conscientemente de los conocimientos. En la narración, por ejemplo, los participantes deben escribir en un papel la solución que se le dará a una tarea propuesta.

3. Situación de validación - La estrategia se demuestra a los interlocutores, es decir, el alumno no solo debe comunicar información, sino que también necesita afirmar que lo que dice es 
cierto dentro de un sistema dado. A través del cuento, los alumnos se apropian de una forma diferente a lo que se les cuenta y la forma en que resuelven las tareas.

4. Situación de institucionalización - Aquí aparece el carácter probabilístico de lo que los niños validaron, es decir, es una síntesis de lo construido durante el proceso y tiene un significado socialmente establecido. En este caso, el docente/investigador tiene un papel activo, seleccionando y organizando las situaciones que serán registradas.

Consideramos importante destacar qué es una situación problema, que según Almouloud (2016) forma parte de una situación adidáctica, al estar constituida por un conjunto de preguntas abiertas y/o cerradas formuladas en un contexto más o menos matematizado, involucrando un campo de problemas ubicados en uno o más dominios del conocimiento.

Almouloud (2016) continúa diciendo que su función principal es el uso implícito, y luego explícito, de nuevos objetos matemáticos, a través de las preguntas de los estudiantes a la hora de resolver un problema. Deben comprender los datos del problema y comprometerse en su resolución utilizando sus conocimientos disponibles, poniendo en juego un campo conceptual que se desea explorar y en el que se inserta el conocimiento objetivo. Es fundamental que el alumno se dé cuenta de que sus conocimientos previos son insuficientes para la resolución inmediata del problema y, además, el conocimiento, le brinda las herramientas convenientes para obtener la solución final.

Según la TSD, el docente no debe simplemente comunicar conocimientos, sino devolver un buen problema (Freitas, 2008). Esta devolución supone la transferencia de la responsabilidad de resolver el ejercicio al alumno. El profesor anuncia la actividad al alumno, pero, además, actúa de tal forma que el alumno asume el reto de resolver el ejercicio. Si el alumno acepta participar en este desafío intelectual y si tiene éxito en su empresa, entonces comienza el proceso de aprendizaje (Freitas, 2008).

Todavía nos inspira la TSD (Brousseau, 1996), para elaborar y proponer situaciones que involucran diferentes visiones de probabilidad, siendo estas visiones: clásica o laplaciana, frecuentista y geométrica, con el fin de contribuir a un aprendizaje que se desarrolle las potencialidades probabilísticas de los estudiantes, ampliando su capacidad para tomar decisiones de una manera que también tiene sentido fuera del contexto escolar y, además, es según Freitas (2008) que a través del análisis de situaciones didácticas es posible investigar el problema del aprendizaje matemático y develar aspectos que ocurren durante la resolución de problemas y la elaboración de conceptos por parte de los estudiantes.

Por tanto, partimos de la TSD que se basa en tres hipótesis: (1) El alumno aprende adaptándose al entorno; (2) El medio sin intenciones didácticas es insuficiente para permitir la adquisición de conocimientos matemáticos; (3) El entorno y las situaciones deben involucrar significativamente el conocimiento matemático involucrado en el proceso de enseñanza y aprendizaje.

Específicamente en relación con la probabilidad, Ribeiro y Goulart (2013) destacan que la concepción clásica de probabilidad está relacionada con los juegos de azar. La concepción frecuentista 
es definida por Lopes y Rezende (2010) como la probabilidad obtenida por un proceso de experimentación y simulación. Ribeiro y Goulart (2013) explican que incluso los juegos de azar, cuando se repiten innumerables veces, llevan a una proporción de veces que ocurre un evento, en idénticas condiciones.

Coutinho (1994) defiende la visión frecuentista de la probabilidad que en su evaluación parece ser más adecuada a un primer contacto con las probabilidades, ya que puede utilizar experimentos vinculados a la realidad de los estudiantes, ya que no necesita estar limitado a la hipótesis de equiprobabilidad. También indica que la presencia de probabilidad frecuentista en la educación se justifica porque forma parte de nuestra vida diaria, ya que el ciudadano se encuentra rodeado de información presente en periódicos, revistas, televisión, internet y noticieros donde se calcula la mayor parte de los datos probabilísticos a través de esta probabilidad.

Coutinho (2001) señala la importancia de la articulación entre dos enfoques cuando el objetivo es la construcción del concepto de probabilidad. El primero (clásico o laplaciano) se refiere a la relación entre el número de aciertos y el número total de casos cuando el espacio muestral es equiprobable, y el segundo es el propuesto por Bernoulli: el valor alrededor del cual la serie de frecuencias relativas acumuladas del evento se estabiliza.

Nunes y Bryant (2012) citan a Fischbein (1987) quien afirma que los niños en edad preescolar tienen intuiciones primarias sobre la naturaleza de eventos aleatorios inciertos, basadas en sus experiencias informales, pero estas intuiciones no siempre son coherentes y conducen a malentendidos por parte de los niños. Sin embargo, son la base del progreso de los niños en la comprensión de la probabilidad y, con la ayuda de la enseñanza, pueden reconstruir las ideas iniciales en intuiciones secundarias, mucho más profundas sobre la probabilidad.

\section{OBJETIVO Y METODOLOGÍA}

En este estudio, el énfasis en la narrativa del cuento histórico és una estrategia para la enseñanza y el aprendizaje de la Probabilidad en los primeros años de Educación Primaria, específicamente, en el cuarto año de Educación Primaria ya que, según Araújo (2015), respeta las características individuales de cada uno de los estudiantes y permite desarrollar la autoconfianza (motivación, interés, atención, participación), autoestima (puedo hacerlo, intentaré hacerlo, investigaré) y autocrítica (momento en el que el alumno evalúa su procedimiento o lo compara con el de su colega); además de promover la contextualización de la temática estudiada con la cotidianidad y la interdisciplinariedad, fomentando la flexibilidad y la creatividad del alumno.

Las siguientes preguntas justifican el uso de la narrativa del cuento histórico y orientan el trabajo luego de abordar el tema: (1) ¿Se pueden trabajar las narrativas del cuento histórico sobre la enseñanza de la probabilidad en los primeros años de la Escuela Primaria? (2) ¿Es posible trabajar el contenido de probabilidad en los primeros años de la escuela primaria propuesto por BNCC a través de cuentos? (3) 
¿Es posible asociar la historia de la probabilidad con la enseñanza de contenidos probabilísticos en los primeros años de la escuela primaria propuesta por BNCC a través de cuentos?

\section{OBJETIVO}

El siguiente trabajo tiene como objetivo indagar en el aprendizaje de los alumnos de cuarto año de Educación Primaria, teniendo en cuenta situaciones que involucran conceptos básicos de probabilidad a través de un cuento histórico.

En esta investigación, la TSD sirvió de soporte para la evaluación de la actividad de intervención de Probabilidades apoyada en el cuento "¿Sabías que los niños jugaban con el juego de las baldosas hace mucho tiempo, en Francia?" (Anexo I) para estudiantes de cuarto año de primaria, buscando el desarrollo de competencias y habilidades relacionadas con las nociones básicas de probabilidad.

Creemos que el TSD permitirá evaluar la construcción del conocimiento probabilístico por parte del alumno, siendo cualitativo como aspecto metodológico y contribuyendo al logro del objetivo que es la apropiación de conceptos probabilísticos dirigidos a estudiantes de primaria.

\section{PARTICIPANTES}

La aplicación del juego se llevó a cabo en una clase con 24 estudiantes de cuarto año de una escuela primaria pública, en la ciudad de Santo André, São Paulo, Brasil. También contamos con la presencia del profesor de la clase.

Consideramos que los estudiantes tuvieron una formación de conceptos probabilísticos, ya que en este ciclo se debe ampliar la exploración de las posibilidades de cuantificar lo incierto. Con las nociones elementales de probabilidad, los estudiantes aprenderán a determinar las posibilidades de que ocurran algunos eventos (monedas, dados, cartas). Así, podrán familiarizarse con el uso de las matemáticas para hacer predicciones y darse cuenta de la importancia de la probabilidad en la vida cotidiana (Ministério de Educación, 1997).

\section{INSTRUMENTO DE EVALUACIÓN}

Para la recolección de datos se utilizaron los siguientes instrumentos: cuento con la narrativa histórica, cuaderno de campo con registros de observaciones realizadas en clase, cuaderno de notas de los participantes y sus manifestaciones orales.

Teniendo en cuenta la dificultad de basarse únicamente en el registro escrito de todas las manifestaciones orales de los niños, ante una situación probabilística, debido a la infinidad de interlocuciones y explicaciones que ofrecen los niños, también optamos por utilizar la grabación de las clases y un transcripción posterior, con el fin de mejorar el trabajo de análisis cualitativo de las manifestaciones (exposiciones, argumentos, toma de decisiones y acciones de los niños), lo que 
permitiría describir si, y en qué medida, los procesos metacognitivos se manifiestan ante la propuesta presentada.

La propuesta didáctica contiene un cuento histórico y para el diseño de cada actividad consideramos la siguiente estructura: (1) El título de la actividad (cuento); (2) El tiempo propuesto para el desarrollo de la actividad; (3) El espacio propuesto para el desarrollo de la actividad; (4) La agrupación (individualmente o en grupos); (5) Los objetivos y contenidos; (6) Análisis didáctico-matemático; (7) Las fases de descripción y aplicación; (8) Los recursos utilizados.

\section{El CUENTO “iSABÍAS QUE HACE MUCHO TIEMPO QUE LOS NIÑOS JUGABAN CON EL JUEGO DE LAS BALDOSAS, EN FRANCIA?"}

Para la elaboración del cuento y análisis según la TSD consideramos la Base Curricular Nacional Común - BNCC (Ministério de Educación, 2018) como un documento curricular dirigido a los primeros años de Educación Primaria, con la intención de desarrollar material pedagógico para el proceso de enseñanza-aprendizaje, específicamente la enseñanza de la probabilidad.

Teniendo en cuenta a Gancho (2006) y Jervis (2017) indicamos a continuación cómo clasificamos la historia: “¿Sabías que los niños jugaban con el juego de baldosas hace mucho tiempo, en Francia?", Según su narrativa, es decir:

1. El cuento se clasifica como transmisión oral, tal y como fue contado y realizado por los investigadores en una clase de cuarto año de primaria.

2. En cuanto a los personajes, los clasificamos de la siguiente manera: i) Conde de Buffon: Personaje principal y según al rol que juega en la trama como protagonista, teniendo características superiores a los demás personajes; ii) Dadito: Personaje secundario que cuenta la historia del personaje principal; iii) Niñas "Clara" y "Cora" y Maestra de Dadito: Participan en la historia como personajes secundarios.

3. En cuanto al narrador, la historia es en primera persona, ya que hay un personaje narrador (Dadito) que cuenta la historia del personaje central y principal (Conde de Buffon) a sus amigas "Clara" y "Cora" (también personajes secundarios).

4. En cuanto al tiempo, se restringe a un intervalo de tiempo ya que el personaje secundario (Dadito) narra un momento que vivió en el aula (docente presentando la historia del Conde de Buffon y el juego de las baldosas) a sus amigas (Clara y Cora).

5. En cuanto a la trama, intentamos presentar un lenguaje sencillo y accesible a los niños de cuarto año de primaria.

6. En cuanto al espacio, la historia es narrada por Dadito en la casa de sus vecinos "Clara" y "Cora", recordando un momento vivido, en el mismo día, en el aula, cuando la maestra contaba la historia del Conde de Buffon y el juego de las baldosas. 
7. En cuanto al género, la historia es infantil, ya que está dirigida a niños (cuarto año de primaria) y a que los niños la escuchen. Y también lo clasificamos como histórico, por estar muy ligado a la realidad, haciendo uso de ciertos matices que permiten que los niños se distraigan un poco de la trama con relación a los hechos reales que realmente sucedieron.

El cuento tiene la propuesta didáctica de centrarse en el desarrollo de contenidos probabilísticos, utilizando como disparador, un juego que fue estudiado por primera vez en 1733 por el naturalista y matemático francés Georges-Louis Leclerc, el Conde de Buffon, presentado por Badizé et al. (1996) como propuesta para introducir la enseñanza de la probabilidad.

El juego, según Coutinho (2002), consiste en lanzar una moneda sobre un piso de baldosas de forma cuadrada donde los jugadores apostarían por la posición final desde la que caería la moneda, es decir, quedaría completamente inmóvil en una sola baldosa (posición denominada "franco-carreau”) o en una junta entre dos baldosas o en más juntas. La figura 1 muestra a los personajes en forma de muñeco de fieltro para que los niños los manipulen.

\section{Figura 1}

Presentación de los personajes de la historia

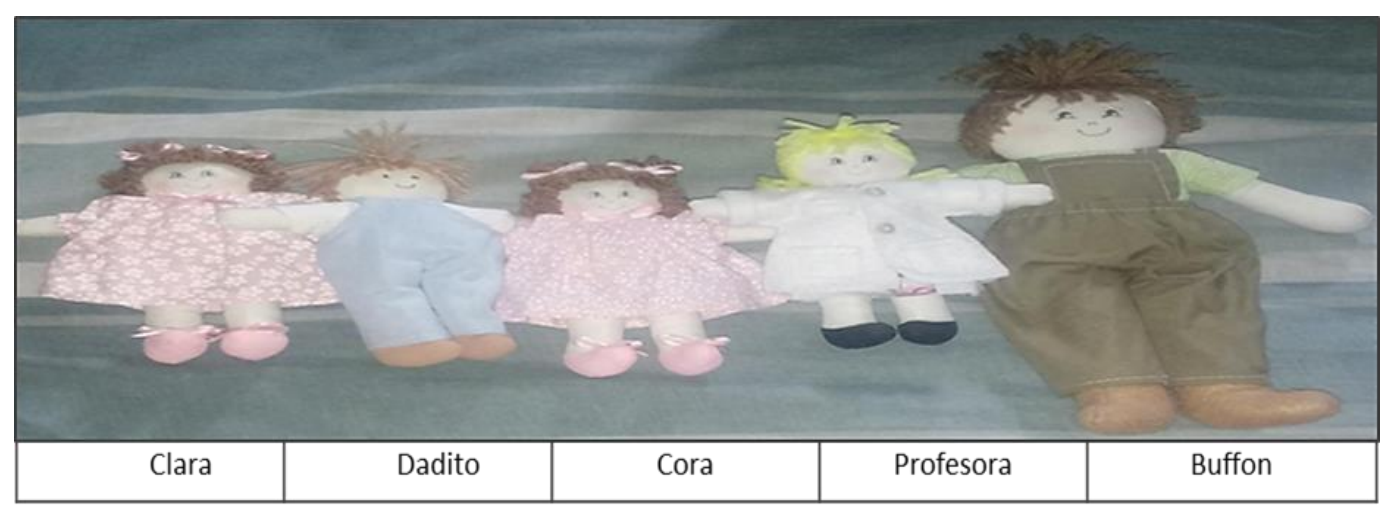

Sigue la representación del tablero o baldosas de un palacio que contribuyó al desarrollo de las actividades propuestas después de que se presentó la historia a los estudiantes (Figura 2)

\section{Figura 2}

Presentación del tablero o representación de las baldosas de un palacio utilizados para realizar las actividades del cuento

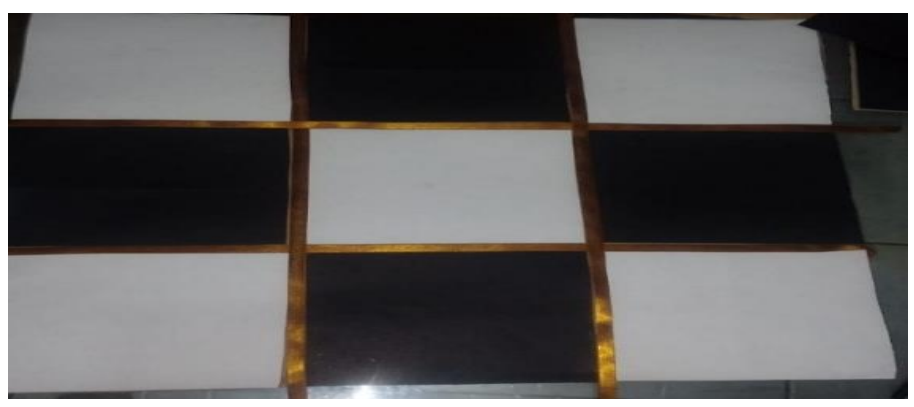




\section{METODOLOGÍA}

Como destaca Chamorro (2005), la metodología basada en TSD es aquella en la que el alumno construye activamente su propio aprendizaje, en colaboración con otras personas, alumnos y profesores. El maestro será parte del proceso de enseñanza-aprendizaje del niño, pero nunca proporcionará conocimientos ya hechos; es el propio alumno quien, a través de las herramientas que le proporciona la historia y que dirige el profesor, construye su aprendizaje. El profesor actuará como mediador del aprendizaje durante el desarrollo de la actividad.

También consideramos que los propios alumnos son los responsables de la construcción de su aprendizaje, es decir, deben partir de situaciones cotidianas y cercanas a la vida del niño.

Por tanto, para que el enfoque sea global, la metodología debe ser activa y significativa, ya que los propios estudiantes deben reconocer la utilidad de los contenidos cubiertos en su vida diaria (Duch, Groh \& Allen, 2001). Es una metodología activa, porque a través de la manipulación y experimentación se lleva a cabo el proceso de enseñanza-aprendizaje, ya que, debido a la corta edad de los niños, consideramos que es la forma más adecuada para llevar a cabo este proceso.

\section{DESCRIPCIÓN DE LA PROPUESTA DIDÁCTICA BASADA EN EL CUENTO “iSABÍAS QUE HACE MUCHO TIEMPO QUE LOS NIÑOS JUGABAN CON EL JUEGO DE LAS BALDOSAS, EN FRANCIA?"}

Para preservar la identidad de los participantes al presentar los resultados y su análisis, se utilizaron nombres en clave. Así, los participantes (estudiantes) fueron nombrados con la letra A y números: A1, A2, A3, ..., A24.

Inicialmente nos presentamos a los estudiantes y les dijimos que habría una actividad para enseñar matemáticas y les preguntamos si les gustaban las matemáticas. La mayoría expresó que les gustaba realizar operaciones matemáticas y quitaron las tablas de multiplicar de sus útiles.

Estas tablas de multiplicar tenían diferentes formatos y se usaban para evaluar el conocimiento matemático básico de la multiplicación y para probar si los estudiantes tenían dominio de los conceptos matemáticos básicos. Notamos que algunos estudiantes tenían los conceptos fundamentados y otros eran más lentos para responder las preguntas.

En ese momento, se buscó una interacción inicial entre investigador y estudiantes para facilitar el desarrollo de la actividad que se desarrollaría a continuación.

Entonces, comenzamos a contar la historia, presentando los personajes: Dadito y las hermanas gemelas Clara y Cora. Les dijeron que Dadito y las hermanas Clara y Cora estudian en el mismo colegio por las mañanas, pero en habitaciones distintas, y que se reúnen en la casa de las niñas todas las tardes para resolver las tareas enviadas a casa, ya que son vecinas. 
En ese momento, presentamos los personajes a los alumnos para que se identificaran con ellos y que en la continuación de la historia pudieran crear su propia identidad con ellos. A los estudiantes se les permitió manipular los muñecos de los personajes y se notó que los estudiantes tenían curiosidad por la historia contada y comenzaron a interactuar con los personajes. Los personajes pasaron de mano en mano.

Continuando con el conteo, se dijo que luego de que Dadito llegara a la casa de las niñas Clara y Cora, recordó la historia del Conde de Buffon que contó su maestra en su salón de clases. En ese momento, también permitimos que los estudiantes manipularan el personaje que era el maestro y para crear una mayor identificación, sugerimos que este maestro sería su profesora Rose.

Se notó que los estudiantes admitieron que este personaje realmente era la profesora Rose, a pesar de que el cabello de la muñeca del personaje era rubio y su maestra tenía la piel y el cabello negros. Esta identificación fue bastante interesante, mostrando que los niños fueron capaces de identificar la profesora con el personaje.

Volviendo al relato, dijimos que Dadito recordó una historia que su maestra contó en su salón de clases esa mañana y se la contó a sus amigas gemelas: Clara y Cora. En ese momento se notó que, principalmente las alumnas se identificaron con los personajes femeninos de la historia.

Así, iniciamos la presentación de la parte del cuento que abordaba aspectos de la historia de la probabilidad y luego presentamos al Conde de Buffon en la figura del muñeco personaje.

Así dijimos que hace mucho tiempo vivió un conde que era abogado, médico y todavía muy aficionado al estudio de la naturaleza, conocido en ese momento como Conde de Buffon, en la corte de Luis XV, rey de Francia en el siglo XVIII, y quien fue designado en 1733 como fundador del Jardín del Rey, hoy llamado Jardín de las Plantas, ubicado en el famoso París.

Para que los alumnos se identifiquen con el período en el que ocurrió la historia y tengan la percepción de que estos lugares existieron y aún existen, les mostramos imágenes del Jardín de Plantas (Figura 3).

\section{Figura 3}

Imágenes antigua $y$ actual del Jardin de Plantas en París (fuente: izquierda: bttps://upload.wikimedia.org/wikipedia/commons/c/c2/Paris - Jardin des Tuileries.jpg; $\quad$ derecha: bttps://r4pbrazil.com/wp-content/uploads/2016/01//ardin Plantes.jpg)

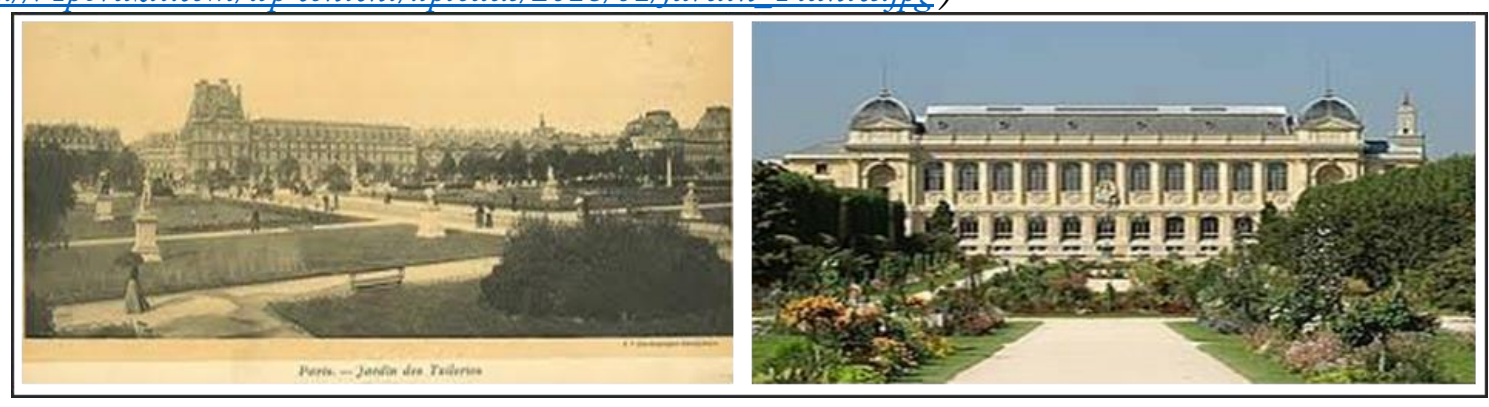


En ese momento, uno de los estudiantes tenía curiosidad por saber dónde estaban París y Francia. De esta manera, pudimos evaluar los conocimientos de geografía de los estudiantes y preguntamos dónde estaba París. Algunos estudiantes dijeron que se quedarían en Francia. Y después de identificar el país llamado Francia, preguntamos en qué continente estaba Francia antes de preguntarle a la profesora Rose si habían estudiado los continentes y ella confirmó que sí.

Entonces, preguntamos dónde estaba Francia y uno de los estudiantes dijo que está en Rusia. Así, volvemos a la pregunta diciendo si estaba en el continente europeo o si estaba cerca de Rusia. Con estas discusiones ya afloran aspectos didácticos (complementarios al medio) a pesar de no ser exactamente los conceptos que pretendíamos estudiar.

Otra pregunta que surgió fue que, habiendo ocurrido la historia en 1733, ¿cuántos años tenía el conde de Buffon? A través de esta pregunta pudimos hacer una operación matemática rápida y el alumno dijo que tenía más de 200 años e incluso preguntó si el conde ya había muerto.

En ese momento discutimos si era posible que una persona mayor de 200 años estuviera viva y llegamos a la conclusión de que el conde no estaba vivo. Otra pregunta que surgió está relacionada con la pronunciación de la palabra Buffon y dijimos que era francesa.

Continuando con el conteo, dijimos que, en un hermoso día, el Conde de Buffon, caminando por el jardín, sufrió una caída y tuvo que permanecer con las piernas en el aire por mucho tiempo. Además de hacer muchas cosas y recordar que era abogado, médico y naturalista, a Buffon le gustaban las matemáticas.

El Conde de Buffon, con las piernas inmovilizadas, para "pasar el tiempo", observó el suelo del jardín formado por baldosas y empezó a tirar al suelo la varilla con la que limpiaba su pipa. Observó que la varilla a veces cruzaba (o tocaba) las líneas de los tabiques entre las baldosas y, en otras ocasiones, esto no sucedía.

Además, les dijimos a los estudiantes que en ese momento a los franceses les gustaban los juegos y que el Conde de Buffon creó el juego de las baldosas y que este juego se llamaba "juego de franc-carreau" y que los niños franceses jugaban mucho en el siglo XVIII. En ese momento, buscando devolver a los alumnos a los ambientes de los palacios con piso de baldosas, les presentamos otras imágenes (Figura 4) con la intención de volver a darse cuenta de que estos ambientes existían y aún existen.

\section{Figura 4}

Imágenes actuales de suelos de baldosas (blanco y negro) en palacios (fuente: https:/leurotrip.com.br/wpcontent/uploads/2019/10/grand-trianon-versalbes.jpg)

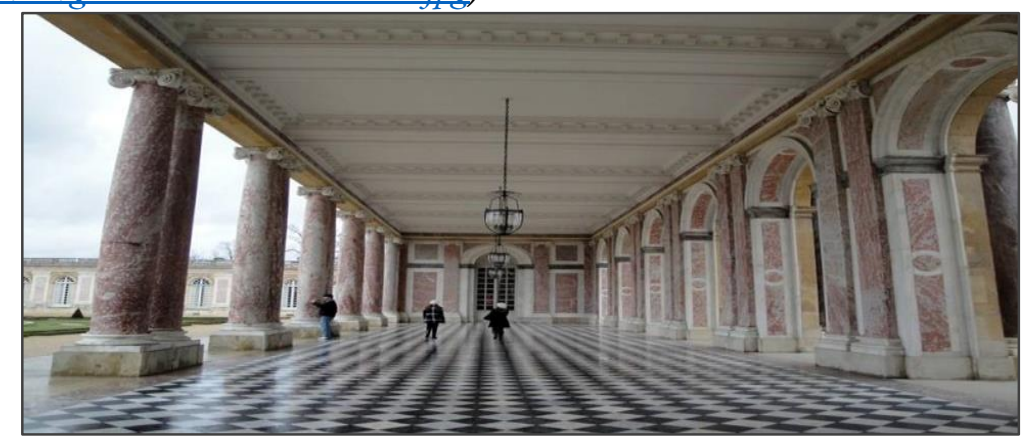


La narración continuó mostrando cómo era el juego y sus reglas, es decir, se tomó una pequeña moneda y se dejó caer al azar en un piso cubierto de baldosas cuadradas. Además, cuando los niños empezaron a jugar al "juego franc-carreau” intentaron adivinar si la moneda caería completamente dentro de una baldosa (franc-carreau) o si la moneda se caería o tocaría el lado de una baldosa.

Es curioso señalar que los niños, sabiendo ya que la historia transcurría en París, Francia, tenían curiosidad por saber escribir "franc-carreau”. Así que fuimos a la pizarra y escribimos la palabra en francés. También es interesante notar que pronunciaron correctamente la palabra que habíamos escrito anteriormente.

Otro tema importante para destacar es que uno de los alumnos nos preguntó cuál era el significado de "franc-carreau", lo cual dijimos que no había una traducción muy precisa, pero que “carreau” se refería a las baldosas y que ese nombre se dio porque el objetivo del juego era que la moneda cayera en la baldosa.

Volviendo a la historia, después de que Dadito contara la historia del Conde de Buffon y recordando que, históricamente, estaba de moda colocar baldosas en los pisos de los castillos y jardines, él y las gemelas pensaron que estas baldosas serían un tablero y que podrían construirse con bastante facilidad.

Así, tomando cuadrados blancos y negros, comenzamos a construir, en algunas partes del aula, tableros que recordaban a los alumnos los pisos de baldosas de los palacios de la época en que vivía el Conde de Buffon (Figura 5).

\section{Figura 5}

Formación de tableros en el aula, referidos a los suelos de los palacios franceses

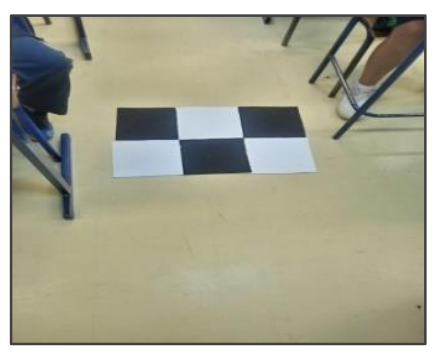

Nota. Foto tomada durante la actividad

Devolvimos a los alumnos al momento presente, Dadito sugirió a las gemelas que repitieran el juego de las baldosas, tirando monedas al azar al suelo y apostando en el tope de monedas dentro del cuadrado de un tablero.

A través del experimento "lanzar la moneda sobre el tablero en forma de baldosas y observar dónde caerá" indica las posibilidades del experimento, al que llamamos espacio muestral del experimento aleatorio. 
Entonces, para terminar de contar la historia y dar continuidad a la aplicación de la actividad, planteamos la siguiente pregunta: ¿Qué factores contribuyeron para que luego de que se caiga una moneda en las baldosas, cayó completamente en una baldosa o sin tocar ninguno de los bordes de los cuadrados de la baldosa (o tablero)?

Destacamos que se abordan los conceptos de probabilidad, como la aleatoriedad o la existencia de fenómenos dependientes de variables, que son parte esencial del pensamiento de probabilidad fuera del paradigma determinista.

De esta forma proponemos a los niños que podrían jugar con el juego franc-carreau y ayudar a Dadito y las hermanas gemelas a tomar sus decisiones. A partir de ese momento, les pedimos a los niños que pusieran sus pupitres en círculo (límites del salón) y que construyeran las tablas en la parte central del salón para que pudieran jugar (Figura 6). También destacamos que el primer momento de la actividad, es decir, contar y escuchar la historia duró unos 30 minutos

\section{Figura 6}

Construcción de cuatro tableros en la parte central del aula para que los alumnos jueguen

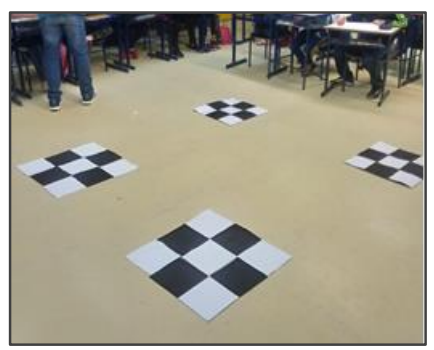

Nota. Foto tomada durante la actividad.

En el transcurso de la narración, percibimos un ambiente propicio para una situación adidáctica, configurando alumnos motivados y discutiendo sus percepciones en ese momento. Durante el conteo, notamos situaciones adidácticas, considerando inicialmente una situación de acción, ya que los estudiantes ponen en práctica sus conocimientos a través de sus percepciones de lo que se les expone. A partir del cuento, llegaron a la conclusión de que la información histórica ayuda en el proceso de apropiación de conceptos probabilísticos, sin ni siquiera ser conscientes de que fueron estos conceptos los que les enseñaron.

\section{REGISTROS ESCRITOS DE ESTUDIANTES, PRESENTACIÓN Y DESARROLLO DE LA ACTIVIDAD DE INTERVENCIÓN}

Además, los estudiantes deben tener una participación activa en la búsqueda del conocimiento, interactuando entre sí, con el docente y con el conocimiento. El objetivo era propiciar un diálogo entre los participantes, llevándolos a reflexionar y discutir los caminos a seguir en la búsqueda de la solución de problemas. 
Explicar conocimientos y confrontar un punto de vista con el de otros compañeros podría resultar una situación favorable para que los participantes se ayuden entre sí, con el fin de superar las dificultades encontradas o los errores cometidos durante la realización de una actividad o la resolución de un problema. En este proceso, el error, cuando se identificó, se consideró una valiosa fuente de información. Esta se configura como una acción y pasa a la formulación descrita en el siguiente párrafo.

Los alumnos recibieron la actividad y para su ejecución respondieron en el cuaderno que se les entregó al inicio de la clase. Siempre que fue necesario, los investigadores intervinieron. En los siguientes subapartados se presenta el relato de la actividad realizada en clase así como el análisis de las situaciones vivenciales.

Los alumnos recibieron la actividad y las respondieron en las hojas de notas que se distribuyeron. Siempre que fue necesario, se contó con la intervención de los investigadores.

Por lo tanto, la actividad propuesta después de la presentación del cuento fue que los estudiantes respondieran lo que consideran más fácil de ocurrir antes del lanzamiento de la moneda. La Figura 7 indica el momento en que los estudiantes respondieron en sus cuadernos lo que consideraron más probable

\section{Figura 7}

Momento de realización de la actividad

Nota. Foto tomada durante la actividad

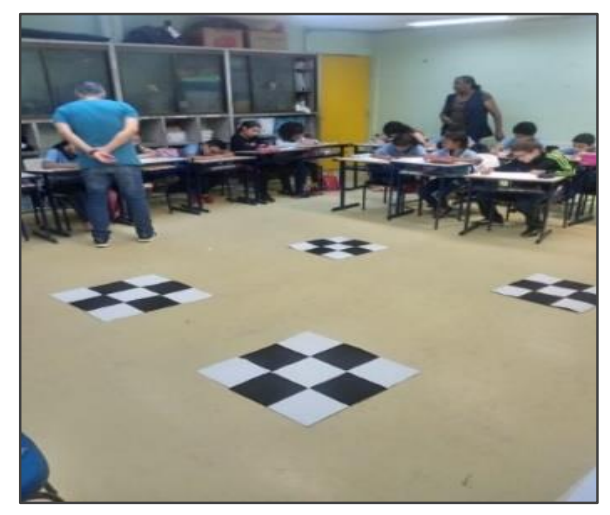

Podemos percibir en el transcurso de la clase un ambiente propicio para una situación adidáctica. Los estudiantes trabajaban individualmente, pero al mismo tiempo ya comenzaban a tener una percepción grupal y a estar motivados por lo propuesto durante la actividad y por los problemas, discutiendo las formas de resolverlo. Es decir, empezaron a interactuar en grupos.

Cuando se planteó la pregunta que indicaría lo que consideran más fácil que ocurra antes del lanzamiento de la moneda, los alumnos se vieron envueltos en una situación de acción, poniendo en práctica sus conocimientos para solucionar el problema. Observamos que comenzaba a emerger un conocimiento que se fundamentaba durante el conteo en información histórica que buscaba ayudar en el proceso de apropiación de conceptos probabilísticos. 
Destacamos que los alumnos debían leer e interpretar el problema propuesto en la historia y movilizar conocimientos previos como la noción de azar, experimento aleatorio, espacio muestral y evento, y esto de forma intuitiva a través de la comprensión del juego de franc-carreau.

Consideramos que los estudiantes vivieron una situación de formulación, ya que fueron llevados a explicar las estrategias utilizadas cuando tuvieron que formularlas por escrito, iniciando la transformación de un conocimiento implícito en uno explícito. Así, los estudiantes retoman su acción y adquieren los conocimientos de forma consciente, buscando una solución a una tarea.

Las respuestas indicadas por los veinticuatro estudiantes participantes dieron como resultado la siguiente información: (1) Once estudiantes dijeron que es más fácil que la moneda caiga en el cuadrado; (2) Ocho estudiantes ampliaron su respuesta indicando que la mayor posibilidad es ser franco-carreau, es decir, que la moneda caiga dentro del cuadrado, trayendo la nomenclatura correcta, en francés, asociando que debe caer dentro del cuadrado. Como ejemplos tenemos: "En mi opinión es más fácil caer en "Franc carreau"; "Dentro del cuadrado, que es Franc Carreau"; (3) Cinco estudiantes dijeron que la moneda caería en el medio, es decir, cruzaría o tocaría el lado de una baldosa.

Identificamos 18 (dieciocho) estudiantes que tenían la percepción correcta de que, dado que el área del cuadrado es mayor que los límites de los cuadrados, hay mayores posibilidades de que la moneda, luego de ser lanzada, caiga dentro del cuadrado. En relación a los alumnos que cometieron errores, monitoreamos su desarrollo durante la actividad, orientando, en la medida de lo posible, haciéndoles preguntas para que pudieran comenzar a apropiarse de los conceptos.

Posteriormente, se propuso a los alumnos que cada uno lanzara la moneda en la pizarra 20 veces y completara la tabla que se proponía en el cuaderno de actividades (Figura 8). En este punto, se movilizaron aspectos de aprendizaje, ya que los estudiantes realizaron un experimento aleatorio cuando lanzaron la moneda y observaron su resultado. 


\section{Figura 8}

Marco propuesto para ayudar en el control del experimento

\begin{tabular}{|c|c|c|}
\hline Lanzamiento & $\begin{array}{c}\text { Fue franc-carreau (cayó en los } \\
\text { cuadrados) }\end{array}$ & $\begin{array}{c}\text { No era franc-carreau (cayó con } \\
\text { alguna parte en los bordes de los } \\
\text { cuadrados) }\end{array}$ \\
\hline \multicolumn{3}{|l|}{1} \\
\hline \multicolumn{3}{|l|}{2} \\
\hline \multicolumn{3}{|l|}{3} \\
\hline \multicolumn{3}{|l|}{4} \\
\hline \multicolumn{3}{|l|}{5} \\
\hline \multicolumn{3}{|l|}{6} \\
\hline \multicolumn{3}{|l|}{7} \\
\hline \multicolumn{3}{|l|}{8} \\
\hline \multicolumn{3}{|l|}{9} \\
\hline \multicolumn{3}{|l|}{10} \\
\hline \multicolumn{3}{|l|}{11} \\
\hline \multicolumn{3}{|l|}{12} \\
\hline \multicolumn{3}{|l|}{13} \\
\hline \multicolumn{3}{|l|}{14} \\
\hline \multicolumn{3}{|l|}{15} \\
\hline \multicolumn{3}{|l|}{16} \\
\hline \multicolumn{3}{|l|}{17} \\
\hline \multicolumn{3}{|l|}{18} \\
\hline \multicolumn{3}{|l|}{19} \\
\hline 20 & & \\
\hline
\end{tabular}

Como se disponía de cuatro tableros en el aula, se propuso que, en parejas, los alumnos realizaran el experimento que llamamos aleatorio, ya que no es posible, previamente, determinar, en cada lanzamiento, si la moneda caería dentro del cuadrado o cruzando el costado de un cuadrado. La Figura 9 muestra momento en lo que los estudiantes realizaron el experimento. Es interesante notar que se sintieron relajados y el experimento se llevó a cabo en el suelo, lo que permitió realizar la actividad sin presión.

\section{Figura 9}

Momento de realización de la actividad del experimento aleatorio propuesto

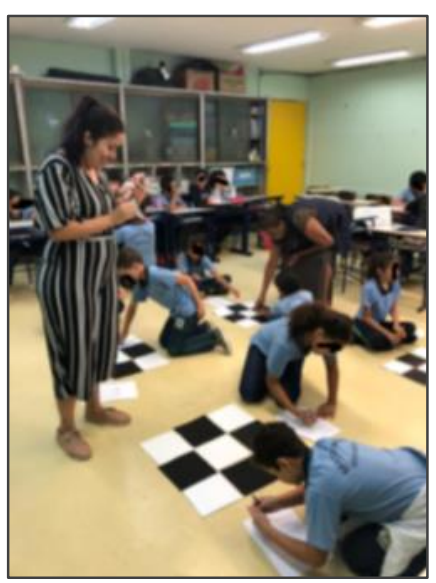

Nota. Foto tomada durante la actividad 
En la Figura 9, donde se inició la visión frecuentista, se puede apreciar que era necesario hacer un seguimiento del desarrollo de la actividad, ya que algunos alumnos no entendían cómo se debía desarrollar la actividad, es decir, en cada lanzamiento debían marcar con una (X) la primera columna si "Fue franco-carreau (cayó dentro de los cuadrados)" o deben marcar la segunda columna si "No fue franco-carreau (cayó con alguna parte en los bordes de los cuadrados)". Aquí fue posible identificar el espacio muestral (todos los resultados posibles del experimento) y los eventos que son subconjuntos de ese espacio muestral.

A continuación, presentamos algunas tablas completadas por los estudiantes para mostrar nuevas situaciones de acción, formulación y validación aditiva que requiere que los estudiantes desarrollen estrategias de resolución de problemas.

En el caso de la validación, a través de las estrategias desarrolladas por los estudiantes, estos deben comunicar información y aún tratar de afirmar que lo que obtuvieron es cierto dentro de un determinado sistema, es decir, a través de la experimentación, cada estudiante se apropia de manera diferente a lo que se experimenta y la forma en que resuelve las tareas propuestas.

Por tanto, la figura 10 indica un ejemplo de la solución presentada por uno de los 19 alumnos que realizó la actividad como se pensó en el desarrollo de la actividad, es decir, que el tablero ayudaría en el control del experimento y que se puede generar otro conocimiento.

\section{Figura 10}

Resultado de la tabla completada por el alumno 1 (A1) (fuente: Elaboración del alumno 1(A1))

\begin{tabular}{|c|c|c|}
\hline Lanzamientos & $\begin{array}{c}\text { Fue Franc-Carreau (Cayó en los } \\
\text { cuadrados) }\end{array}$ & $\begin{array}{c}\text { No fue Franc-Carreau (cayó con alguna parte en los } \\
\text { bordes de los cuadrados) }\end{array}$ \\
\hline 1 & & $\mathrm{X}$ \\
\hline 2 & $\mathrm{X}$ & \\
\hline 3 & $\mathrm{X}$ & \\
\hline 4 & $\mathrm{X}$ & \\
\hline 5 & & $\mathrm{X}$ \\
\hline 6 & $\mathrm{X}$ & \\
\hline 7 & $\mathbf{X}$ & \\
\hline 8 & $\mathbf{X}$ & \\
\hline 9 & & $\mathbf{X}$ \\
\hline 10 & $\mathrm{X}$ & \\
\hline 11 & $\mathrm{X}$ & \\
\hline 12 & $\mathrm{X}$ & \\
\hline 13 & $\mathrm{X}$ & \\
\hline 14 & $\mathrm{X}$ & \\
\hline 15 & & $\mathrm{X}$ \\
\hline 16 & $\mathrm{X}$ & \\
\hline 17 & $\mathrm{X}$ & \\
\hline 18 & $\mathrm{X}$ & \\
\hline 19 & $\mathbf{x}$ & \\
\hline 20 & $\mathrm{X}$ & \\
\hline
\end{tabular}


La Figura 11 indica un ejemplo de solución de los 5 estudiantes que no completaron la tabla como se pensaba en el desarrollo de la actividad, es decir, la tabla no ayudó en el control del experimento. Así, para algunos estudiantes no hubo apropiación de lo propuesto.

\section{Figura 11}

Resultado de la tabla completada por el alumno 8 (A8) (fuente: Elaboración del alumno 8(A8))

\begin{tabular}{|c|c|c|}
\hline Lanzamientos & $\begin{array}{c}\text { Fue Franc-Carreau (Cayó en los } \\
\text { cuadrados) }\end{array}$ & $\begin{array}{c}\text { No fue Franc-Carreau (cayó con alguna parte en los } \\
\text { bordes de los cuadrados) }\end{array}$ \\
\hline 1 & $\mathrm{X}$ & MI y 0 \\
\hline 2 & $\mathrm{X}$ & $\mathrm{X}^{*}$ \\
\hline 3 & $\mathbf{X}$ & $\mathrm{X}^{*}$ \\
\hline 4 & $\mathrm{X}$ & $\mathrm{X}$ " \\
\hline 5 & $\mathrm{X}$ & $\mathrm{X}^{*}$ \\
\hline 6 & $\mathrm{X}$ & $\mathrm{X}^{*}$ \\
\hline 7 & $\mathrm{X}$ & $\mathrm{X}^{*}$ \\
\hline 8 & $\mathbf{X}$ & \\
\hline 9 & $\mathrm{X}$ & \\
\hline 10 & $\mathrm{X}$ & \\
\hline 11 & $\mathrm{X}$ & \\
\hline 12 & $\mathrm{X}$ & \\
\hline 13 & $\mathrm{X}$ & \\
\hline 14 & $\mathrm{X}$ & \\
\hline 15 & $\mathrm{X}$ & \\
\hline 16 & $\mathrm{X}$ & \\
\hline 17 & $\mathrm{X}$ & \\
\hline 18 & $\mathrm{X}$ & \\
\hline 19 & $\mathrm{X}$ & \\
\hline 20 & $\mathrm{X}$ & \\
\hline
\end{tabular}

En la secuencia sugerimos una tabla resumen para que los estudiantes se den cuenta de que los veinte experimentos podrían resumirse en dos casos posibles: (1) Moneda cayendo en el cuadrado (franco-carreau) o (2) Moneda cayendo o tocando el costado de un azulejo. Todavía es posible notar: (1) El número de casos posibles (todos los lanzamientos); (2) El número de casos favorables a franc-carreau; y (3) El número de casos no favorables a franco-carreau.

La figura 12 muestra la asociación entre las tablas de la actividad propuesta por uno de los estudiantes entre los 22 estudiantes que lograron completar esta parte de la actividad de una manera que consideramos correcta 


\section{Figura 12}

Asociación entre tablas 1 y 2 de la actividad por parte del alumno 11 (A11) (fuente, Elaboración del alumno 11 (A11))

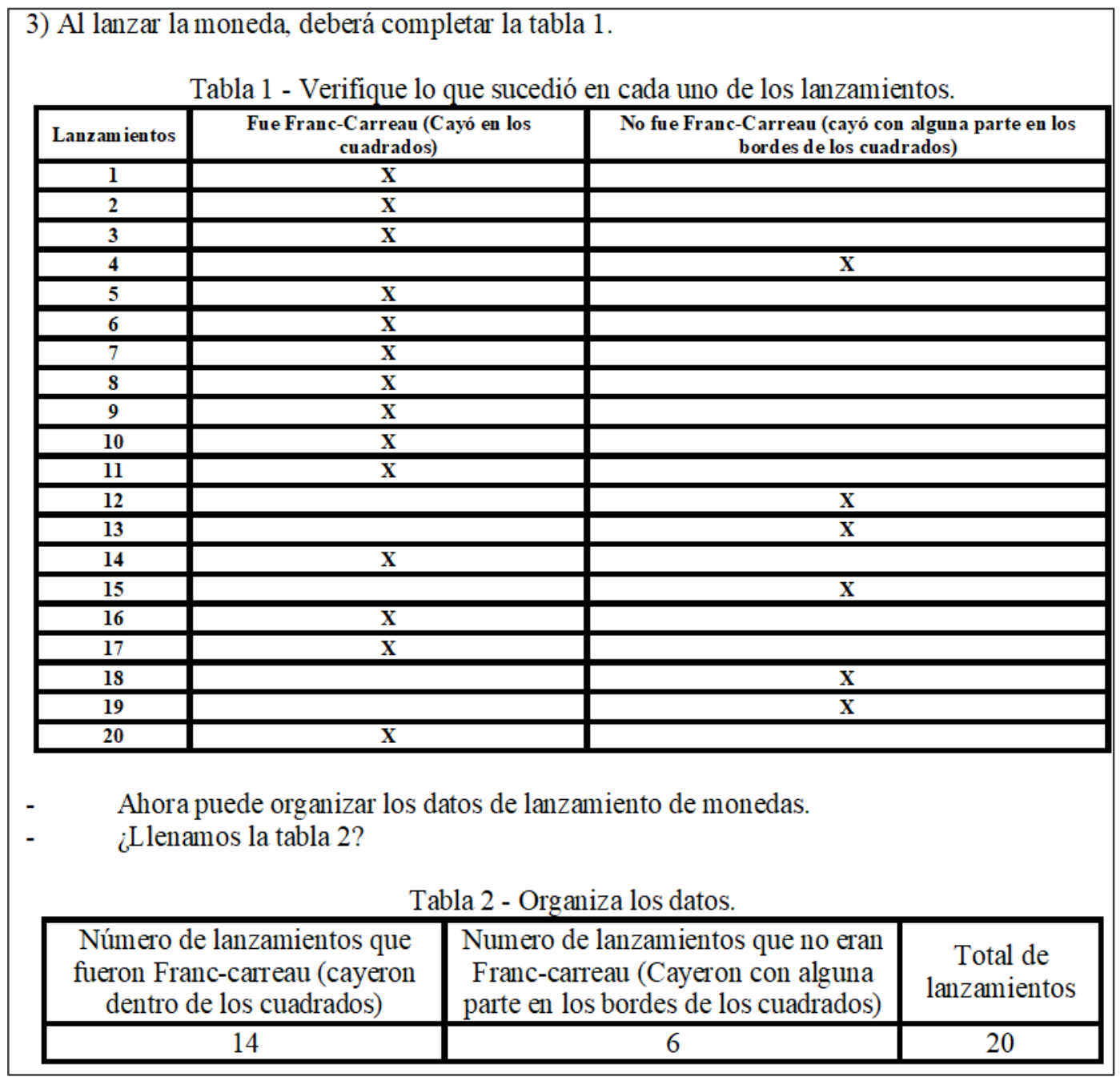

La figura 13 muestra la asociación entre las tablas de la actividad propuesta de uno de los dos alumnos que no pudo completar correctamente esta parte de la actividad. 


\section{Figura 13}

Asociación entre tablas 1 y 2 de la actividad por parte del alumno 23 (A23) (fuente, Elaboración del alumno 23 (A23))

\begin{tabular}{|c|c|c|}
\hline Lanzamientos & $\begin{array}{l}\text { Fue Franc-Carreau (Cayó en los } \\
\text { cuadrados) }\end{array}$ & $\begin{array}{c}\text { No fue Franc-Carreau (cayó con alguna parte en los } \\
\text { bordes de los cuadrados) }\end{array}$ \\
\hline 1 & $\mathbf{x}$ & $\mathbf{x}$ \\
\hline 2 & $\bar{x}$ & $\bar{x}$ \\
\hline 3 & $\bar{x}$ & \\
\hline 4 & $\mathbf{x}$ & \\
\hline 5 & $\mathbf{X}$ & \\
\hline 6 & $\mathbf{x}$ & \\
\hline 7 & $\mathbf{x}$ & $\mathbf{x}$ \\
\hline 8 & $\mathrm{X}$ & $\bar{x}$ \\
\hline 9 & $\bar{x}$ & $\mathrm{X} \mathrm{X}$ \\
\hline 10 & $\mathbf{X}$ & $\mathbf{X}$ \\
\hline 11 & $\begin{array}{ll}\mathbf{X} & \mathbf{X} \\
\end{array}$ & $\bar{x}$ \\
\hline 12 & $\mathbf{X}$ & $\mathbf{X} \mathbf{x}$ \\
\hline 13 & $\mathbf{x}$ & X X \\
\hline 14 & $\mathbf{x}$ & $\mathbf{x}$ \\
\hline 15 & & $\mathbf{X}$ \\
\hline 16 & $\mathbf{x}$ & \\
\hline 17 & & $\bar{x}$ \\
\hline 18 & $\bar{x}$ & \\
\hline 19 & $\bar{x}$ & \\
\hline 20 & $\bar{x}$ & \\
\hline
\end{tabular}

- $\quad$ Ahora puede organizar los datos de lanzamiento de monedas.

- $\quad$ ¿Llenamos la tabla 2 ?

Tabla 2 - Organiza los datos.

Número de lanzamientos que fueron Franc-carreau (cayeron dentro de los cuadrados)
Numero de lanzamientos que no eran Franc-carreau (Cayeron con alguna parte en los bordes de los cuadrados) 18 12

Total de lanzamientos

En ese momento, los estudiantes comenzaron a trabajar, de manera más efectiva, de manera conjunta, en la que se formaron los grupos y se comenzaron a consolidar conceptos que anteriormente no estaban formalizados correctamente Se inició una percepción grupal y quedó la motivación para las actividades, generando discusiones para buscar la solución de los problemas.

Cerrando la actividad, se propusieron algunas preguntas con el fin de evaluar si los estudiantes se habían apropiado de los conceptos presentados anteriormente, es decir, aquí se expresa una situación de institucionalización adidáctica, con el objetivo de que aparezca el carácter probabilístico de lo que los niños validaron, o que sea, es una síntesis de lo construido durante el proceso y tiene un significado socialmente establecido. En este caso, los investigadores jugaron un papel activo en la selección y organización de las situaciones a registrar.

La pregunta propuesta era buscar que los estudiantes establecieran conocimientos, comparando lo que tenían como premisa antes de que se realizara el experimento y después del experimento. Entonces se hizo la siguiente pregunta: “¿Hubo alguna diferencia entre lo que pensaba que sucedería antes de 
lanzar la moneda y lo que realmente sucedió después de lanzar la moneda? Explicar". En la Tabla 1 se muestran las opiniones de los alumnos, antes y después del experimento, es decir, lanzando la moneda y observando dónde caería.

Tabla 1

Opiniones de los estudiantes, antes y después del experimento, es decir, lanzar la moneda y observar dónde caería y evaluar esta percepción

\begin{tabular}{|c|c|c|c|}
\hline $\mathbf{n}$ & $\begin{array}{l}\text { Opinión antes de } \\
\text { realizar el } \\
\text { experimento }\end{array}$ & $\begin{array}{l}\text { Opinión tras realizar el } \\
\text { experimento }\end{array}$ & $\begin{array}{l}\text { Evaluación de la percepción de los alumnos } \\
\text { después del experimento realizado en } \\
\text { relación con lo considerado antes de su } \\
\text { desempeño }\end{array}$ \\
\hline 1 & Dentro del cuadrado. & $\begin{array}{l}\text { Sí, porque pensé que se iba a caer por } \\
\text { un lado del cuadrado y se cayó. }\end{array}$ & $\begin{array}{l}\text { Confirmó su percepción inicial y que era } \\
\text { correcta. }\end{array}$ \\
\hline 2 & $\begin{array}{l}\text { Caer dentro del } \\
\text { cuadrado }\end{array}$ & Sí, fue un juego genial. & $\begin{array}{l}\text { Confirmó su percepción inicial y que era } \\
\text { correcta. }\end{array}$ \\
\hline 3 & $\begin{array}{l}\text { Caer dentro del } \\
\text { cuadrado }\end{array}$ & Pasó más de lo que pensaba. & $\begin{array}{l}\text { Confirmó e avanzó en su percepción inicial, } \\
\text { que era correcta. }\end{array}$ \\
\hline 4 & Dentro del cuadrado. & $\begin{array}{l}\text { Sí, porque pensé que iba a haber más } \\
\text { franco-carreau. }\end{array}$ & $\begin{array}{l}\text { Confirmó e avanzó en su percepción inicial, } \\
\text { que era correcta. }\end{array}$ \\
\hline 5 & Franc Carreau. & $\begin{array}{l}\text { Sí, porque es más fácil caer en el } \\
\text { cuadrado. }\end{array}$ & $\begin{array}{l}\text { Confirmó su percepción inicial y que era } \\
\text { correcta. }\end{array}$ \\
\hline 6 & $\begin{array}{l}\text { Caer dentro del } \\
\text { cuadrado. }\end{array}$ & $\begin{array}{l}\text { Pensé que iba a caer cuadrado, pero } \\
\text { cayó en ambos. }\end{array}$ & $\begin{array}{l}\text { Confirmó e avanzó en su percepción inicial, } \\
\text { que era correcta. }\end{array}$ \\
\hline 7 & $\begin{array}{l}\text { Caer dentro del } \\
\text { cuadrado. }\end{array}$ & $\begin{array}{l}\text { Sí, cae dentro. Porque el cuadrado es } \\
\text { más grande. }\end{array}$ & $\begin{array}{l}\text { Confirmó e avanzó en su percepción inicial, } \\
\text { que era correcta. }\end{array}$ \\
\hline 8 & En el medio. & [No respondio] & $\begin{array}{l}\text { [El alumno tenía un problema en la vista y en el } \\
\text { supuesto de que se trataba de conjuntivitis el } \\
\text { docente decidió que debía salir del aula.] }\end{array}$ \\
\hline 9 & $\begin{array}{l}\text { Dentro del cuadrado, } \\
\text { que es Franc Carreau. }\end{array}$ & $\begin{array}{l}\text { Sí, porque pensé que iba a haber un } \\
\text { empate y lo hizo y también cayó más } \\
\text { en el cuadrado. }\end{array}$ & $\begin{array}{l}\text { Confirmó e avanzó en su percepción inicial, } \\
\text { que era correcta. }\end{array}$ \\
\hline 10 & Caer en franc carreau. & $\begin{array}{l}\text { Pensé que caería } 11 \text { veces en el franco- } \\
\text { carreau, pero cayó más y cometí } \\
\text { menos errores de los que esperaba. }\end{array}$ & $\begin{array}{l}\text { Confirmó e avanzó en su percepción inicial, } \\
\text { que era correcta. }\end{array}$ \\
\hline 11 & Franc Carreau. & Sí, lo que pensé sucedió. & $\begin{array}{l}\text { Confirmó su percepción inicial y que era } \\
\text { correcta. }\end{array}$ \\
\hline 12 & Dentro. & Sí. & $\begin{array}{l}\text { Confirmó su percepción inicial y que era } \\
\text { correcta. }\end{array}$ \\
\hline 13 & Franc Carreau. & Sí. & $\begin{array}{l}\text { Confirmó su percepción inicial y que era } \\
\text { correcta. }\end{array}$ \\
\hline 14 & $\begin{array}{l}\text { Caer dentro del } \\
\text { cuadrado. }\end{array}$ & $\begin{array}{l}\text { No. Porque como pensaba que era, } \\
\text { ese era el juego. }\end{array}$ & $\begin{array}{l}\text { Confirmó su percepción inicial y que era } \\
\text { correcta, aunque seguía confundido en los } \\
\text { argumentos. }\end{array}$ \\
\hline 15 & En el medio. & Pensé que era diferente. & $\begin{array}{l}\text { Cambió su concepto erróneo inicial a través del } \\
\text { experimento realizado. }\end{array}$ \\
\hline
\end{tabular}




\begin{tabular}{|c|c|c|c|}
\hline 16 & $\begin{array}{l}\text { Caer dentro del } \\
\text { cuadrado. }\end{array}$ & $\begin{array}{l}\text { No, porque llegué a los cuadrados } 14 \\
\text { veces. }\end{array}$ & $\begin{array}{l}\text { Confirmó e avanzó en su percepción inicial, } \\
\text { que era correcta. }\end{array}$ \\
\hline 17 & $\begin{array}{l}\text { En mi opinión es más } \\
\text { fácil caer en "franc } \\
\text { carreau". }\end{array}$ & $\begin{array}{l}\text { En mi opinión, tenía la idea de que } \\
\text { caería más dentro del cuadrado } \\
\text { porque es más grande. }\end{array}$ & $\begin{array}{l}\text { Confirmó su percepción inicial y que era } \\
\text { correcta. }\end{array}$ \\
\hline 18 & Franc Carreau. & Sí, pensé que iba a caer más. & $\begin{array}{l}\text { Confirmó e avanzó en su percepción inicial, } \\
\text { que era correcta. }\end{array}$ \\
\hline 19 & En el medio. & Sí, porque cayó en el lugar que pensé. & $\begin{array}{l}\text { Continúa con la percepción errónea de la } \\
\text { mayor posibilidad de ocurrencia, a pesar de } \\
\text { haber realizado el experimento. }\end{array}$ \\
\hline 20 & Franc Carreau. & $\begin{array}{l}\text { Tenía. Pensé que lo sería, pero } \\
\text { cuando lancé la moneda fue genial. }\end{array}$ & $\begin{array}{l}\text { Confirmó su percepción inicial y que era } \\
\text { correcta. }\end{array}$ \\
\hline 21 & En el medio. & Era diferente. & $\begin{array}{l}\text { Cambió su concepto erróneo inicial a través del } \\
\text { experimento realizado. }\end{array}$ \\
\hline 22 & $\begin{array}{l}\text { Caer dentro del } \\
\text { cuadrado. }\end{array}$ & Sí, iba a haber más franco-carreau. & $\begin{array}{l}\text { Confirmó su percepción inicial y que era } \\
\text { correcta. }\end{array}$ \\
\hline 23 & En el medio. & Sí, fue un juego genial. & $\begin{array}{l}\text { Cambió su concepto erróneo inicial a través del } \\
\text { experimento realizado. }\end{array}$ \\
\hline 24 & Dentro del cuadrado. & No, cayó al cuadrado. & $\begin{array}{l}\text { Confirmó su percepción inicial y que era } \\
\text { correcta, a pesar de decir que no después de que } \\
\text { se realizó el experimento. }\end{array}$ \\
\hline
\end{tabular}

Destacamos que las partes sombreadas en la Tabla 1 se refieren a aquellos estudiantes que inicialmente tuvieron la actividad incorrecta y, luego de realizado el experimento, se percibió la comprensión del concepto.

Se observa después de esta actividad que solo un alumno aún no se ha dado cuenta de que el área del cuadrado es mayor, lo que indica que existe una mayor probabilidad de que la moneda caiga en este espacio en lugar de que la moneda caiga o toque el lado de un cuadrado. En el desarrollo de la clase, los estudiantes comienzan a tener una percepción de conceptos básicos de probabilidad como la aleatoriedad de un experimento, en la medida en que no se puede garantizar que la moneda caiga o toque uno de los cuadrados del tablero.

También hay un indicio de que los estudiantes perciben que hay dos posibilidades (francocarreau y no franco-carreau) en el lanzamiento de la moneda en la pizarra, además de comenzar a valorar que cada una de estas posibilidades tiene una mayor o menor probabilidad de ocurrencia.

El problema propuesto a continuación buscaba evaluar si los estudiantes percibían intuitivamente el concepto de espacio muestral y sus eventos después de hacer la siguiente pregunta: "¿Cuáles son las posibilidades que observaste al lanzar la moneda?".

De las respuestas a la pregunta anteriormente señalada, se observa que solo 13 estudiantes de los 23 que actualmente estaban participando en la actividad, indicaron en su respuesta que se dieron cuenta de que hay dos posibilidades en el lanzamiento de la moneda y ya perciben intuitivamente el concepto de espacio muestral. Presentamos a continuación lo que escribieron y que indica esta percepción: 
A2: Puedo hacerlo bien dentro del cuadrado y en la línea.

A3: Caer más en el cuadrado.

A4: Esa hora ganas y otra hora pierde.

A5: Cae sobre la línea y el cuadrado.

A9: Que caiga más en el cuadrado.

A10: Ella podría haberse retirado cada vez que jugué.

A12: Cae entre los cuadrados y dentro del cuadrado.

A14: Que tiré la moneda fuera del cuadrado, dentro del cuadrado.

A15: Pensé que iba a perder.

A16: Que se pueda ir y también que se pueda caer en la plaza.

A18: Que iba a abandonar más a menudo.

A22: Jugando el franco-carreau.

A23: Puedo hacerlo bien dentro del cuadrado y en la línea.

Es interesante notar que dos estudiantes registraron que habría tres posibilidades diferentes y que no podemos considerar erróneo el concepto, ya que indicaron que las tres posibilidades son: (1) caer en el cuadrado (franc-carreau); (2) caer fuera del cuadrado (no franco-carreau) y dentro del tablero; (3) caer fuera del tablero.

Otros siete estudiantes indicaron solo una de las posibilidades, presentando esa posibilidad o evento (subconjunto del espacio muestral) que es el más probable, es decir, todavía pensando solo en esa posibilidad. Los escritos de estos estudiantes son los siguientes:

A1: Eso caería en el cuadrado.

A7: Cae en el cuadrado.

A11: La moneda puede caer en franco-carreau.

A13: Cayó hacia adentro.

A17: Posibilidad de caer en el cuadrado.

A24: Cae en el cuadrado.

Finalmente, dos estudiantes presentaron respuestas que demuestran que no entendieron la pregunta propuesta, indicando que aún necesitan consolidar el conocimiento enfocado en los conceptos básicos de probabilidad. Los escritos de estos estudiantes indican que la actividad fue difícil.

\section{CONSIDERACIONES FINALES}

Creemos que el desarrollo de esta investigación consistió en la elección de fundamentos teóricos que posibilitarían un aporte a la enseñanza y aprendizaje de los conceptos fundamentales de probabilidad para el cuarto año de Educación Primaria en Brasil. La elección recayó en la Teoría de las Situaciones Didácticas - TSD de Guy Brousseau a través de la elaboración de un cuento histórico y, 
posteriormente, actividades de apropiación de conceptos básicos de probabilidad con miras a la autonomía de los estudiantes en la construcción de sus conocimientos.

La TSD también brindó condiciones favorables a los investigadores para que, entre otras tareas, pudieran elaborar, aplicar, monitorear y realizar análisis de las actividades aplicadas, en las que se invitaba al alumno a construir conocimientos relacionados con un contenido probabilístico, sin la interferencia directa del maestro.

Los investigadores y los estudiantes firmaron un contrato didáctico, con los investigadores como mediadores y los estudiantes se comprometieron a apropiarse de los conocimientos propuestos en la ejecución de las actividades propuestas. Por lo tanto, se hizo necesario que el estudio resultara atractivo para el alumno y considerara la realidad en la que estaba inmerso. En la TSD, la identificación del error es valiosa, ya que permite la elaboración de nuevas situaciones problemáticas que pueden hacer más efectiva la apropiación del conocimiento.

Los investigadores desarrollaron un cuento histórico y una actividad que cubría conceptos y procedimientos probabilísticos. Por tanto, se contó la historia y se aplicó la actividad en un aula con 24 alumnos.

Observando la autonomía y capacidad de los estudiantes, consideramos que desarrollaron sus propias estrategias en la resolución de las actividades propuestas, en la búsqueda de información y en la seguridad para la toma de decisiones. Se observaron las acciones de los estudiantes, encaminadas a la búsqueda de alternativas a posibles impasses que surgieron durante la realización de las actividades.

Es importante señalar que buscamos brindar a los estudiantes actividades que les permitan construir su propio conocimiento a través de un proceso de interacción entre colegas y entre ellos y este conocimiento.

El análisis de los datos de la investigación destacó la participación de los estudiantes en actividades sobre conceptos probabilísticos, cumpliendo con todas las actividades propuestas, discutiéndolas con colegas e investigadores. De hecho, el análisis de los datos de la investigación mostró que, incluso en momentos en que la tarea presentaba mayores desafíos, los estudiantes no se rendían.

La implicación se observó explícitamente, por ejemplo, cuando los participantes desarrollaron, sin interferencia de los investigadores, la actividad de cumplimentar la tabla que resumía los resultados del experimento aleatorio "tirar la moneda al tablero y observar dónde cae" realizado por cada uno de los estudiantes.

En la categoría de satisfacción de los participantes, se verificó su entusiasmo por la realización de las actividades. Todos los estudiantes demostraron que disfrutaban trabajando en grupo, realizando tareas juntos. Salvo uno de los alumnos, manifestó que no le gustó la historia y las actividades, porque según él, no se debe vivir en el pasado, sino pensar en el futuro, además de considerar que los aspectos de ganar o ganar perder el juego debería ser más claro. 
Durante el análisis, surgió la categoría de interacción, mostrando que ocurrió tanto entre los estudiantes como entre ellos y los investigadores. Se observó que la interacción entre estudiantes se presentó de forma cooperativa durante casi todo el trabajo en grupo. Tales resultados mostraron que este tipo de ordenamiento de clases constituía un fuerte inductor de interacción y cooperación entre ellos.

En la interacción se observaron discusiones y esfuerzos de los estudiantes por colaborar con el crecimiento de los colegas, apuntando a la construcción del conocimiento. La relación entre estudiantes e investigadores se estableció de forma directa y comunicativa. Se mantuvo una relación de respeto, complicidad y diálogo constante en la solución de las actividades desarrolladas a lo largo de la investigación, que contribuyeron al proceso de enseñanza y aprendizaje.

La relación del estudiante con el conocimiento probabilístico fue fundamental, y esta relación se manifestó de dos formas: 1) El reconocimiento de la importancia del conocimiento probabilístico; 2) La apropiación de ese conocimiento. Los estudiantes se dieron cuenta de la importancia de los conocimientos estudiados durante el desarrollo de las actividades.

Aunque algunos estudiantes expresaron dificultades para adquirir algunos de estos conocimientos, el análisis de los datos indicó que hubo una apropiación de conocimientos por parte de la mayoría de ellos. Cabe señalar que la interacción y cooperación entre los estudiantes, así como la interacción entre ellos y los investigadores, fueron factores que demostraron ser importantes en la adquisición de conocimientos.

Indicamos que, en respuesta a la pregunta de investigación, se puede decir que los resultados obtenidos proporcionaron una fuerte evidencia de que las actividades contribuyeron a la enseñanza y aprendizaje de la Probabilidad en el cuarto año de la escuela primaria. Además, los resultados mostraron las dificultades experimentadas por algunos de los estudiantes en la adquisición de conocimientos, y los errores cometidos nos llevaron a pensar en diferentes enfoques para la apropiación de conocimientos.

Finalmente, creemos que la narrativa incorporada al cuento a través del uso de un juego histórico provocó a los estudiantes aprendieran conceptos probabilísticos. Nos dimos cuenta de que se sentían motivados con los instrumentos utilizados, conduciendo, en general, a la apropiación de los conceptos probabilísticos abordados.

Con esto, indicamos que fue posible trabajar el contenido de probabilidad en los primeros años de la escuela primaria que propone el BNCC a través de un cuento histórico. Se pudo notar que los estudiantes se apropiaron de la historia desarrollada, que percibieron un hecho histórico y que fueron capaces de captar los conceptos probabilísticos.

Además, consideramos que fue posible asociar la historia de la probabilidad con la enseñanza de contenidos probabilísticos en los primeros años de la escuela primaria propuesta por la BNCC a través del cuento. También existe la idea de que se puedan aplicar las mismas actividades a los alumnos de un 
año anterior al aplicado en este trabajo, trayendo los análisis y ajustes necesarios para la apropiación de conceptos.

\section{ACLARATORIAS}

Los autores no tienen conflicto de interés que declarar. El artículo ha sido financiado con recursos propios de los autores.

\section{REFERENCIAS}

Almouloud, S. A. (2014). Fundamentos da Didática da Matemática. Editora UFPR.

Almouloud, S. A. (2016). Modelo de ensino/aprendizagem baseado em situaçôes-problema: aspectos teóricos e metodológicos. Revemat: Revista Eletrônica de Educação Matemática, 11(2), 116141. https://doi.org/10.5007/1981-1322.2016v11n2p109

Alsina, Á., \& Vásquez, C. (2017). Lenguaje probabilístico: un camino para el desarrollo de la alfabetización probabilística. Un estudio de caso en el aula de Educación Primaria. Bolema: Boletim de Educação Matemática, 31(57), 454-478. https://doi.org/10.1590/1980$\underline{4415 v 31 n 57 a 22}$

Araújo, W. R. (2015). O caso dos quatro quatros como uma possibilidade pedagógica para o desenvolvimento de competências e habilidades Matemáticas [Trabalho de Graduação em Licenciatura em Matemática, Universidade Estadual Paulista]. https://repositorio.unesp.br/bitstream/handle/11449/123011/000820248.pdf? sequence=1\& isAllowed $=\mathrm{y}$

Badizé, M., Jacques, A., Petitpas, M., \& Pichard, J.-F. (1996). Le jeu du franc-carreau - une activité probabiliste au Collège. IREM de Rouen.

Batanero, C. (2015). Understanding randomness: challenges for research and teaching. In K. Krainer \& N. Vondrová (Eds.), IX Congress of European Research in Mathematics Education (pp. 3449). CERME. http://www.ugr.es/ batanero/documentos/cerme-lecture.pdf

Booker, G. (2000). The Maths Game: Using instructional games to teach mathematics. New Zealand Council for Educational Research.

Bragg, L. (2007). Students' conflicting attitudes towards games as a vehicle for learning mathematics: a methodological dilemma. Mathematics Education Research Journal, 19(1), 29-44. https://doi.org/10.1007/BF03217448

Brousseau, G. (1978). L'observation des activités didactiques. Revue française de pédagogie, 45, 129139. https://doi.org/10.3406/rfp.1978.1669 
Brousseau, G. (1986). Fondements et méthodos de la didáctique des mathématiques. Reacherches en didáctique des mathématiques, 7(2), 33-115. https://revue-rdm.com/1986/fondements-etmethodes-de-la/

Brousseau, G. (1996). Fundamentos e Métodos da Didáctica da Matemática. (M. J. Figueiredo, trad.). In: J. Brun. Didática das Matemáticas (pp. 35-113). Instituto Piaget. (Trabajo original publicado en 1985).

Chamorro, M. C. (2005). Didáctica de las Matemáticas. Educación Infantil. Pearson.

Coutinho, C. Q. S. (1994). Introdução ao Conceito de Probabilidade por uma Visão Frequentista [Tese de Mestrado, Pontifícia Universidade Católica de São Paulo]. https://sapientia.pucsp.br/bitstream/handle/11159/1/dissertacao_cileda_coutinho.pdf

Coutinho, C. Q. S. (2001). Introduction aux situations aléatoires dès le collège: de la modélisation à la simulation d'expériences de Bernoulli dans l'environnement informatique Cabri-géomètre II [Tese de Doutorado, Université Joseph Fourier]. https://cutt.ly/yYJCPPO

Coutinho, C. Q. S. (2002). Probabilidade Geométrica: Um contexto para a modelização e a simulação de situações aleatórias com Cabri [Artigo apresentado]. 25a Reunião Anual da Associação Nacional de Pós-Graduação e Pesquisa em Educação (ANPED), Caxambu, Minas Gerais, Brasil. http://www.anped.org.br/app/webroot/files/probabilidade.pdf

Coutinho, C. Q. S. (2007). Conceitos probabilísticos: Quais contextos a história nos aponta. Revemat: Revista Eletrônica de Educação Matemática, 2(3), 50-67. https://doi.org/10.5007/\%25x

Duch, B. J., Groh, S. E., \& Allen, D. E. (2001). The Power of Problem Based Learning. Stylus.

Estés, C. P. (2005). A terapia dos contos. Rocco.

Fischbein, E. (1987). Intuition in science and mathematics: An educational approach. Reidel Pub.

Freire, J. B., \& Scaglia, A. J. (2003). Educação como prática corporal. Scipione.

Freitas, J. L. M. (2008). Teoria das Situações Didáticas. In: S. D. A. Machado, (Org.) Educação Matemática: uma (nova) Introdução (pp. 77-111). Editora da PUC-SP (EDUC).

Gancho, C. V. (2006). Como Analisar Narrativas. Ática.

Jervis, T. M. (2017). Clasificación de los Cuentos: Los Géneros Principales. https://www.lifeder.com/clasificacion-cuentos/

Kamii, C., \& Rummelsburg, J. (2008). Arithmetic for first graders lacking number concepts. Teaching Children Mathematics, 14(7), 389-394. https://doi.org/10.5951/TCM.14.7.0389 
Lopes, J. M., \& Rezende, J. C. (2010). Um novo jogo para o estudo do raciocínio combinatório e do cálculo de probabilidade. Bolema: Boletim de Educação Matemática, 23(36), 657- 682. https://repositorio.unesp.br/bitstream/handle/11449/71807/2-s2.079960240757.pdf? sequence $=1 \&$ isAllowed $=y$

Mateus, A. N. B. et al. (2013). A importância da contação de história como prática educativa na educação infantil. Pedagogía em Ação, 5(1), 54-69.

Miguel, A. (1997). As potencialidades pedagógicas da história da matemática em questão: argumentos reforçadores e questionadores. Zetetiké, 5(8), 73-105. https://periodicos.sbu.unicamp.br/ojs/index.php/zetetike/article/view/8646848/13749

Ministério de Educación. (1997). Parâmetros Curriculares Nacionais (1aa 5aa séries). MEC/SEF, Brasília, Brasil. http://portal.mec.gov.br/seb/arquivos/pdf/livro03.pdf

Ministério de Educación. (2018). Base Nacional Comum Curricular (BNCC): Educação é a Base. Brasília, Brasil. http://basenacionalcomum.mec.gov.br/images/BNCC_EI_EF_110518_versaofinal_site.pdf

Nunes, T., \& Bryant, P. (2012). Children's understanding of probability: a literature review (full report). Nuffield Foundation. https://www.nuffieldfoundation.org/sites/default/files/files/Nuffield_CuP_FULL_REPOR Tv FINAL.pdf

Oliveira Júnior, A. P., Delalíbera, B. C. S., \& Cardoso, K. M. (2017). Potencialidades pedagógicas da história da matemática para o ensino de estatística na educação básica. Revista Cocar, 11(22), 13-34. https://periodicos.uepa.br/index.php/cocar/article/view/1593

Pulos, S., \& Sneider, C. (1994). Designing and evaluating effective games for teaching science and mathematics: an illustration form coordinate geometry. Focus on Learning Problems in Mathematics, 16(3), 23-42. https://eric.ed.gov/?id=EJ 495462

Ribeiro, C. E., \& Goulart, A. (2013). O ensino de probabilidade por meio de jogos na educação de Jovens e Adultos. In C. R. Ferreira \& R. R. Costa (Eds.), XI Encontro Nacional de Educação Matemática (pp. 1-15). SBEM-Brasil. http://sbem.iuri0094.hospedagemdesites.ws/anais/XIENEM/pdf/298 733 ID.pd

Vásquez, C. \& Alsina, A. (2014). Enseñanza de la probabilidad en educación primaria. Un desafío para la formación inicial y continua del profesorado. Números, 85, 5-23. http://www.sinewton.org/numeros/numeros/85/Articulos 01.pdf

Viali, L. (2008) Algumas considerações sobre a origem da teoria da probabilidade. Revista Brasileira de História da Matemática, 8(16), 143-153. https://cutt.ly/WYJCDhB 


\section{Cómo citar este artículo:}

Oliveira Júnior, A. P. de, \& Barão, K. M. C. (2021). El cuento histórico para la enseñanza de la probabilidad en la educación primaria en Brasil. Revista Venezolana de Investigación en

Educación Matemática (REVIEM), 1(1), e202111. https://doi.org/10.54541/reviem.v1i1.3 


\section{Anexos}

\section{CUENTO - ¿SABÍA QUE LOS NIÑOS JUGARON CON EL JUEGO DE LA BALDOSA DURANTE MUCHO TIEMPO EN FRANCIA?}

Dadito y las hermanas Clara y Cora estudian por las mañanas en la misma escuela, pero en aulas diferentes, y se reúnen todas las tardes en la casa de las niñas Clara y Cora para trabajar en los trabajos que se envían a casa. Son vecinos.

Al llegar a la casa de las niñas Clara y Cora, Dadito recordó la historia del Conde de Buffon que la Profesora les contó a los alumnos en su salón de clases.

Dadito, recordando la historia, les dice a las niñas Clara y Cora:

- Cuenta la historia que un abogado, médico y que todavía amaba estudiar la naturaleza, conocido en ese momento como el Conde de Buffon, en la corte de Luis XV, rey de Francia en el siglo XVIII, fue nombrado en 1733 director de la Jardín del Rey, hoy en día el Jardín de las Plantas, ubicado en el famoso París.

- Un buen día, paseando por el jardín, Buffon sufrió una caída y tuvo que permanecer con las piernas en el aire durante varios meses. Además de hacer muchas cosas, a Buffon le gustaban mucho las matemáticas.

- Entonces, mientras sus piernas estaban inmovilizadas, para "pasar el tiempo", observó el piso del jardín formado por baldosas y comenzó a tirar al piso la varilla con la que limpiaba su pipa. Observó que el tallo, que tenía la misma longitud que el ancho de las baldosas, a veces cruzaba (o tocaba) las líneas de los tabiques entre las baldosas y, en otras ocasiones, esto no sucedía.

- Además, hay que recordar que en ese momento a los franceses les gustaban los juegos y el Conde de Buffon creó el juego de las baldosas.

- El juego de las baldosas (o franc-carreau) fue ampliamente jugado por los niños franceses en el siglo XVIII.

- El juego fue el siguiente: Cogiste una moneda que fue lanzada al azar en un piso cubierto por baldosas cuadrados. Los niños apostaron a que la moneda caería completamente en una baldosa (franc-carreau) o que la moneda caería o tocaría el lado de una baldosa.

Luego de que Dadito contara la historia del Conde de Buffon y recordando que, históricamente, estaba de moda suelos de baldosas en los castillos y jardines, los niños no perdieron el tiempo y pronto pensaron que estas baldosas serían un gran tablero como el que podemos ver en la siguiente figura:

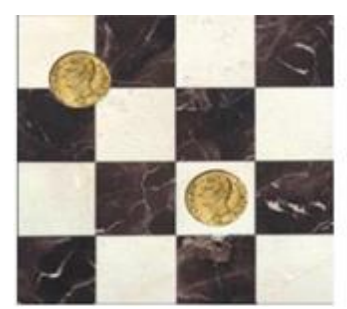

Así, pensaron en repetir el juego de las baldosas, tirar monedas al azar al suelo y apostar al tope de 
monedas dentro de una baldosa (cuadrado de un tablero).

Pero los niños se detuvieron a pensar: ¿Qué factores contribuyeron para que uno de ellos pudiera ganar la apuesta y ver su moneda enteramente dentro de una baldosa, en un tiro al azar, sin tocar ninguno de los bordes de los cuadrados de la baldosa?

- ¿Vamos a ayudar a los niños a tomar una decisión? 


\section{EL CUENTO HISTÓRICO PARA LA ENSEÑANZA DE LA PROBABILIDAD EN...}

cc) (i)

Copyright @ 2021. Ailton Paulo de Oliveira Júnior, Karoline Marcolino Cardoso Barão. Esta obra está protegida por una licencia Creative Commons 4.0. International (CC BY 4.0).

Usted es libre para Compartir — copiar y redistribuir el material en cualquier medio o formato - y Adaptar el documento - remezclar, transformar y crear a partir del material — para cualquier propósito, incluso para fines comerciales, siempre que cumpla la condición de:

Atribución: Usted debe dar crédito a la obra original de manera adecuada, proporcionar un enlace a la licencia, e indicar si se han realizado cambios. Puede hacerlo en cualquier forma razonable, pero no de forma tal que sugiera que tiene el apoyo del licenciante o lo recibe por el uso que hace de la obra.

$\underline{\text { Resumen de licencia - Texto completo de la licencia }}$ 